\title{
Author Correction: Performance metrics for sustainable catalysis in industry
}

\author{
Jean-Paul Lange (D)
}

Correction to: Nature Catalysis https://doi.org/10.1038/s41929-021-00585-2, published online 22 March 2021.

In the version of this Comment originally published, in Fig. 4 the product prices were mistakenly given in euros rather than US dollars. This has now been corrected and text has been added to the figure caption to explain how the prices were converted from euros to US dollars. The corrected figure is shown below.
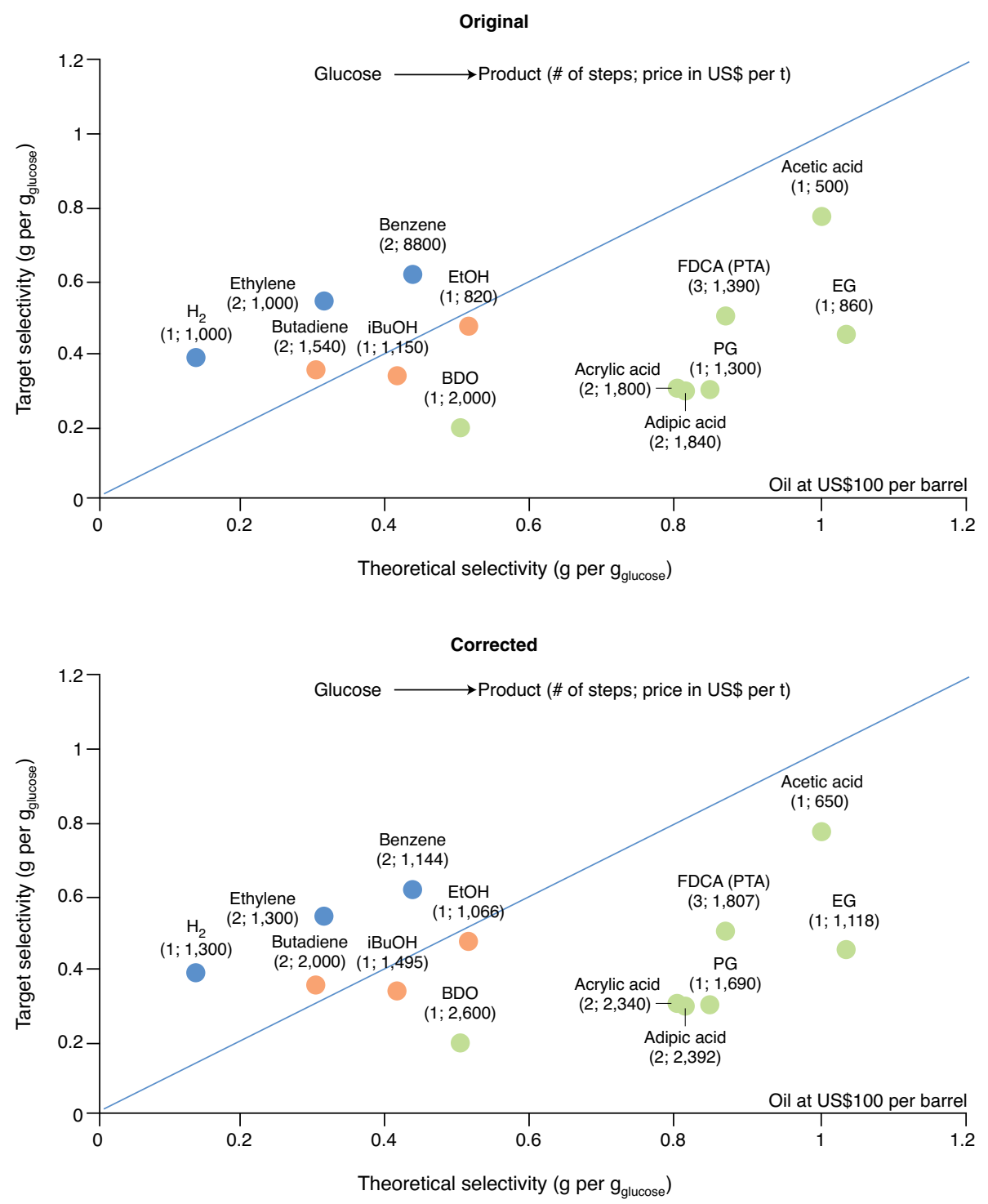

Fig. 4 | Original and Corrected.

Published online: 14 May 2021

https://doi.org/10.1038/s41929-021-00634-w

(C) The Author(s), under exclusive licence to Springer Nature Limited 2021 